\title{
Omega-3 fatty acids, polymorphisms and lipid related cardiovascular disease risk factors in the Inuit population
}

Iwona Rudkowska ${ }^{1,2}$, Catherine Ouellette ${ }^{1}$, Eric Dewailly ${ }^{3}$, Robert A Hegele ${ }^{4}$, Véronique Boiteau ${ }^{3}$, Ariane Dubé-Linteau ${ }^{3}$, Belkacem Abdous ${ }^{3}$, Françoise Proust ${ }^{3}$, Yves Giguère $^{3}$, Pierre Julien ${ }^{2}$, Marie-Ludivine Château-Degat ${ }^{3}$ and Marie-Claude Vohl $1^{1,2^{*}}$

\begin{abstract}
Background: Tissue concentrations of fatty acids (FAs) and genetic variations are well-known factors which affect the cardiovascular disease (CVD) risk. The objective was to examine whether the genetic variability of 20 candidate genes and red blood cells (RBCs) percentage of total $n-3$ polyunsaturated fatty acids (PUFA), a biomarker of dietary n-3 PUFA intake, modulate lipid related CVD risk factors in the Inuit population.

Methods: Data from the Qanuippitaa Nunavik Health Survey $(n=553)$ were analysed via multivariate regression models with 40 known polymorphisms, RBCs percentage of $n-3$ PUFA, and the interaction term to take into account the effect on plasma lipid and apolipoporotein levels.
\end{abstract}

Results: Individuals being heterozygotes for CETP C-4502T (rs183130) or G-971A (rs4783961) together with higher n-3 PUFA had lower triacylglycerol (TG) concentrations compared to homozygotes for the minor allele. Further, effects of a stronger beneficial association between $n$-3 PUFA in RBCs and plasma lipid parameters- including lower total cholesterol (TC), lower low-density lipoprotein cholesterol (LDL-C) or higher high-density lipoprotein cholesterol (HDL-C) concentrations- were associated with AGT M235T (rs699) TT genotype, CETP G-971A (rs4783961) AG genotype, T allele carriers of CETP C-4502T (rs183130), and T allele carriers of CETP lle405Val (rs5882). In contrast, higher n-3 PUFA in RBCs were associated with adverse lipid profiles- including increased LDL-C, increased apolipoprotein B100 or decreased HDL-C concentrations- in G allele carriers of the APOA5 -3 A/G (rs651821), C allele carriers of APOA5 T-1131C (rs662799), G carriers of APOC3 Sstl (rs5128) and G carriers of APOA4 Asn147Ser (rs5104).

Conclusion: Overall, these results suggest that percentage of total $n-3$ PUFA of RBCs are associated with lipids related CVD risk factors conferred by genetic variations in the Inuit population.

Keywords: Nutrigenetics, n-3 PUFAs, Plasma lipids, Gene-nutrient interactions

\section{Background}

The lifestyle of the Inuit is rapidly changing towards an increased cardiovascular (CVD) risk factor profile [1]. The CVD risk factors include non-modifiable risk factors such as age, male sex, family history, and modifiable risk factors for example smoking, hypertension, diabetes, and hyperlipidemia. Specifically, improving plasma lipids

\footnotetext{
* Correspondence: marie-claude.vohl@fsaa.ulaval.ca

${ }^{1}$ Institute of Nutrition and Functional Foods (INAF), Laval University, 2440,

boulevard Hochelaga, Québec QC, Canada

${ }^{2}$ Laboratory of Endocrinology and Nephrology, Laval University Hospital

Research Center, Quebec, QC, Canada

Full list of author information is available at the end of the article
}

profile- including: total cholesterol (TC), triacylglycerol (TG), low-density-lipoprotein cholesterol (LDL-C), apolipoprotein (apo) B concentrations, apo A1 concentrations and high-density-lipoprotein cholesterol (HDL-C)is associated with a decreased CVD risk [2]. Studies have shown that both environmental and genetic factors may play a role in determining susceptibility to dyslipidemia.

The consumption of fish and marine mammals rich in n-3 PUFAs represents an important dietary component for CVD risk prevention in the Inuit population [3]. A high intake of $n-3$ polyunsaturated fatty acids (n-3 PUFAs), including eicosapentaenoic acid (EPA) (20:5(n-3))

\section{Biomed Central}


and docosahexaenoic acid (DHA) (22:6(n-3)), has been shown to exert favorable effects on plasma lipid profiles [4]. Recently, a study confirmed that higher percentages of $n-3$ PUFA content in red blood cells (RBCs) were indicative of higher $n$-3 PUFA intake in the Inuit population [5]. Nonetheless, an increased risk of lipid related CVD is currently occurring despite the substantial proportion of the population maintaining traditional lifestyles including high intakes of $n$-3 PUFAs [6].

The Inuit populations also carry a unique distinct genetic background [7]. This genetic makeup has been shown in some studies to be protective; yet, others have reported potentially detrimental effects for CVD susceptibility $[1,8]$. These genetic variations may render an individual more or less responsive to changes in $n$ - 3 PUFA intake. Thus, gene-nutrient interactions may provide important insights into the inter-individual variability observed in plasma lipid levels and thus on the risk of CVD. Consequently, the main objective of this study was to examine whether the genetic variability of 20 candidate genes in lipid metabolism and percentage of total $n$-3 PUFA in RBCs - a biomarker of dietary $n-3$ PUFA intake, are associated with CVD risk factors including TG, TC, LDL-C, HDL-C, ratio TC/HDL-C and apoB100 concentrations.

\section{Methods}

\section{Subjects}

The data were collected in the framework of the Nunavik Inuit Health Survey "Qanuippitaa? How are we?" conducted among the Inuit of Nunavik in 2004. The survey covered all 14 Nunavik communities [6]. In the winter of 2009, participants from the Qanuippitaa Nunavik Health Survey in 2004 were revisited for the additional genetic component. Participants signed a consent form before data collection. Sampling strategies for the present population-based study have been described previously in detail [9]. All consent and assent forms were approved by the Ethics Committee on Research of Laval University and the Québec Public Health Ethics review board.

\section{Anthropometric measurements}

Height was measured using a rigid square and a measuring tape in a standardized standing position, with the participant's back against the wall looking straight ahead, and arms hanging down freely. Body weight was measured with a scale (Tanita TBF-300, Manufacturer, Arlington Heights, IL). Body mass index (BMI) was calculated as weight per meter squared $\left(\mathrm{kg} / \mathrm{m}^{2}\right)$, and internationally recommended cutoffs were used [10].

\section{Plasma blood sampling}

Blood samples were collected from an antecubital vein into vacutainer tubes containing EDTA. Plasma was separated by centrifugation $\left(2500 \mathrm{x}\right.$ g for $10 \mathrm{~min}$ at $4^{\circ} \mathrm{C}$ ) and samples were portioned and frozen for subsequent measurements. Plasma TC and TG concentrations were determined by enzymatic methods using a Hitachi 917 autoanalyser and reagents from Roche Diagnostics (Canada) [11]. The HDL-C fraction was obtained directly by precipitation with dextran sulfate-Mg2+ procedure [11]. The LDL-C was calculated with the Friedewald formula [12]. ApoB concentrations were measured in plasma by the rocket immunoelectrophoretic method of Laurell [13]. Lipid analyses were performed at the Centre de Recherche sur les Maladies Lipidiques (Centre de Recherche du CHUQ, Quebec, Qc, Canada).

\section{Food frequency questionnaire (FFQ)}

A food-frequency questionnaire (FFQ) [14] was administered to the participants. A specifically designed 69-item FFQ was used to assess average food and beverage intakes during the previous year, as described in more details elsewhere [15]. Analysis of the FFQ data provided estimates of consumption frequency and the usual intake in grams of country foods on a daily, weekly, monthly, seasonal or an annual basis. Daily food intakes were calculated on an annual basis by multiplying food consumption frequency by intake in grams for each food.

\section{Fatty acid determination}

Fatty acid (FA) composition of erythrocyte membranes was determined by gas chromatographic analysis. Membranes of lysed erythrocytes were isolated by centrifugation (21,000g, 15 minutes) and washed twice with $0.9 \%$ $\mathrm{NaCl}$ solution. Cell membranes were resuspended in 200 $\mu \mathrm{L}$ of the $\mathrm{NaCl}$ solution and were spiked with phosphatidylcholine C:15 (Avanti Polar Lipids, Alabaster, AL), used as internal standard. Lipids were extracted using a mixture of chloroform-methanol $(2: 1 \mathrm{v} / \mathrm{v})$ according to a modified Folch method [16]. FA profiles were obtained after methylation in methanol/benzene 4:1 (v/v) [17] and capillary gas chromatography using a temperature gradient on a HP5890 gas chromatograph (Hewlett Packard, Toronto, Canada) equipped with a HP-88 capillary column $(100 \mathrm{~m} \times 0.25 \mathrm{~mm}$ i.d. x $0.20 \mu \mathrm{m}$ film thickness; Agilent Technologies, Palo Atto, CA) coupled with a flame ionization detector (FID). Helium was used as carrier gas (split ratio 1:80). FA were identified according to their retention time, using the following standard mixtures as a basis for comparison: the FAME $37 \mathrm{mix}$ (Supelco Inc., Bellefonte, PA) and the GLC-411 fatty acid mix (NuChek Prep Inc, Elysian, MN), as well as the following methylated fatty acids C22:5 n-6 (Larodan AB, Malmö, Sweden) and C22:5 n-3 (Supelco Inc., Bellefonte, PA). Erythrocyte FA profiles were expressed as the relative percentage areas of total FAs. Total percentage of $n$ 3 PUFAs in RBCs was calculated from the sum of C18:3 
Table 1 Genes, polymorphisms and the main function their protein

\begin{tabular}{|c|c|c|}
\hline Genes (Official symbol) & Polymorphisms & Main function of their protein \\
\hline Angiotensin I converting enzyme (ACE) & I/D alleles (rs4343) & Involved in regulating blood pressure \\
\hline \multirow[t]{4}{*}{ Angiotensinogen (AGT) } & M235T (rs699) & \multirow[t]{4}{*}{ Involved in regulating blood pressure } \\
\hline & T174M (rs4762) & \\
\hline & A-20C (rs5050) & \\
\hline & A-6G (rs5051) & \\
\hline \multirow[t]{2}{*}{ Apolipoprotein A-I (APOA1) } & G-75A (rs670) & \multirow[t]{2}{*}{ Component of $\mathrm{HDL}$ particles } \\
\hline & $84 \mathrm{~T} / \mathrm{C}(\mathrm{rs} 5070)$ & \\
\hline Apolipoprotein A-IV (APOA4) & Asn147Ser (rs5104) & Activates lecithin-cholesterol acyltransferase (LCAT) \\
\hline \multirow[t]{4}{*}{ Apolipoprotein A-V (APOA5) } & T-1131C (rs662799) & \multirow[t]{4}{*}{ Determinant of plasma TG level } \\
\hline & $-3 \mathrm{~A} / \mathrm{G}(\mathrm{rs} 651821)$ & \\
\hline & S19W (rs3135506) & \\
\hline & Gly185Cys (rs2075291) & \\
\hline Apolipoprotein B (APOB) & Xbal (rs693) & Component of LDL particles \\
\hline \multirow[t]{2}{*}{ Apolipoprotein C-III (APOC3) } & Sstl (rs5128) & \multirow[t]{2}{*}{ Major component of TG-rich lipoproteins } \\
\hline & T-455C (rs2854116) & \\
\hline \multirow[t]{3}{*}{ Apolipoprotein E (APOE) } & Cys112Arg (rs429358) & \multirow{3}{*}{$\begin{array}{l}\text { Acts as a ligand receptor in the process of catabolism of } \\
\text { lipoproteins }\end{array}$} \\
\hline & Arg158Cys (rs7412) & \\
\hline & G-219T (rs405509) & \\
\hline $\begin{array}{l}\text { ATP-binding cassette, sub-family } A(A B C 1) \text {, } \\
\text { member } 1 \text { ( } A B C A 1)\end{array}$ & Arg219Lys (rs2230806) & $\begin{array}{l}\text { Transports cholesterol and phospholipids through the cell } \\
\text { membrane to outside the cell }\end{array}$ \\
\hline \multirow{5}{*}{$\begin{array}{l}\text { Cholesteryl ester transfer protein, plasmatique } \\
\text { (CEPT) }\end{array}$} & TaqIB (rs708272) & \multirow[t]{5}{*}{ Transfers cholesterol between lipoproteins } \\
\hline & C-629A (rs1800775) & \\
\hline & C-4502T (rs183130) & \\
\hline & G-971A (rs4783961) & \\
\hline & Ile405Val (rs5882) & \\
\hline \multirow{2}{*}{$\begin{array}{l}\text { Cytochrome P450, family 1, subfamily A, } \\
\text { polypeptide } 1 \text { (CYP1A1) }\end{array}$} & Msp1 (rs4646903) & \multirow{2}{*}{$\begin{array}{l}\text { Catalyses reactions involved in drug metabolism and } \\
\text { synthesis of cholesterol, steroids and other lipids }\end{array}$} \\
\hline & A4889G (rs1048943) & \\
\hline Fat mass and obesity associated (FTO) & rs9939609 & Linked to obesity and diabetes \\
\hline Glucokinase (hexokinase 4) regulator (GCKR) & rs780094 & Inhibitor and glucokinase \\
\hline Insulin induced gene 2 (INSIG2) & rs7566605 & $\begin{array}{l}\text { Connected to the metabolism of lipids, cholesterol, and } \\
\text { obesity }\end{array}$ \\
\hline \multirow[t]{2}{*}{ Lipoprotein lipase (LPL) } & HindIII (rs320) & \multirow[t]{2}{*}{ Hydrolyses TG-rich lipoproteins } \\
\hline & Ser447Ter (rs328) & \\
\hline \multirow[t]{2}{*}{ Lipase (hepatic) (LIPC (HL)) } & C-514T (rs1800588) & \multirow[t]{2}{*}{ Hydrolyses TGs and phospholipids of plasma lipoproteins } \\
\hline & G-250A (rs2070895) & \\
\hline $\begin{array}{l}\text { Methylenetetrahydrofolate reductase }(\mathrm{NAD}(P) H) \\
\text { (MTHFR) }\end{array}$ & C677T (rs1801133) & $\begin{array}{l}\text { Catalyzes the conversion of a co-substrate for } \\
\text { homocysteine }\end{array}$ \\
\hline \multirow[t]{3}{*}{ Paraoxonase 1 (PON1) } & L55M (rs854560) & \multirow[t]{3}{*}{ Reduces LDL-oxidation } \\
\hline & Gln192Arg (rs662) & \\
\hline & C-107T (rs705379) & \\
\hline \multirow{2}{*}{$\begin{array}{l}\text { Peroxisome proliferator-activated receptor gamma } \\
2 \text { (PPARG2) }\end{array}$} & Pro12Ala (rs1801282) & \multirow[t]{2}{*}{ Regulator of adipocyte differentiation } \\
\hline & -681 C/G (rs10865710) & \\
\hline Transcription factor 7-like 2 (TCF7L2) & C47833T (rs7903146) & Transcription factor \\
\hline
\end{tabular}


(n-3), C18:4 (n-3), C20:4 (n-3), C20:5 (n-3) (EPA), C22:3 (n-3), C22:5 (n-3) (docosapentaenoic acid (DPA)), and C22:6 (n-3) (DHA).

\section{DNA extraction and genotyping}

DNA was extracted from $100 \mu$ l of buffy coat using the QIAamp 96 DNA Blood Kit (QIAGEN Inc., Valencia, CA, USA). Quant-iT PicoGreen ${ }^{\circledR}$ dsDNA Assay Kit (Invitrogen) was used to quantify DNA. DNA was analysed with TaqMan ${ }^{\circledR}$ Pre-Designed SNP Genotyping Assays according to the manufacturer's instructions at the McGill University/Génome Québec Innovation Center (Montreal, Canada).

From a literature review, 40 polymorphisms in 20 genes relating to lipid metabolism were identified (Table 1) namely: Angiotensin I converting enzyme (ACE) I/D alleles (rs4343), Angiotensinogen (AGT) M235T (rs699), T174M (rs4762), A-20C (rs5050), A-6G (rs5051); Apolipoprotein A-I (APOA1) G-75A (rs670), 84 T/C (rs5070); Apolipoprotein A-IV (APOA4) Asn147Ser (rs5104); Apolipoprotein A$V$ (APOA5) T-1131C (rs662799), -3 A/G (rs651821), S19W (rs3135506), Gly185Cys (rs2075291); Apolipoprotein $B$ (APOB) XbaI (rs693); Apolipoprotein C-III (APOC3) SstI (rs5128), T-455C (rs2854116); Apolipoprotein E (APOE) Cys112Arg (rs429358), Arg158Cys (rs7412), G-219T (rs405509); ATP-binding cassette, sub-family A (ABC1), member 1 (ABC1A) Arg219Lys (rs2230806); Cholesteryl ester transfer protein (CETP) TaqIB (rs708272), C-629A (rs1800775), C-4502T (rs183130), G-971A (rs4783961), Ile405Val (rs5882); Cytochrome P450, family 1, subfamily A, polypeptide 1 (CYP1A1) Msp1 (rs4646903), A4889G (rs1048943); Fat mass and obesity associated (FTO) (rs9939609); Glucokinase (hexokinase 4) regulator (GCKR) (rs780094); Insulin induced gene 2 (INSIG2) (rs7566605); Lipoprotein lipase (LPL) HindIII (rs320), Ser447Ter (rs328); Hepatic lipase (HL or LIPC) C-514T (rs1800588), G-250A (rs2070895); Methylenetetrahydrofolate reductase $(\mathrm{NAD}(\mathrm{P}) \mathrm{H})$ (MTHFR) C677T (rs1801133); Paraoxonase 1 (PON1) L55M (rs854560), Gln192Arg (rs662), C-107T (rs705379); Peroxisome proliferator-activated receptor gamma 2 (PPARG2) Pro12Ala (rs1801282), 681 C/G (rs10865710); Transcription factor 7-like 2 (TCF7L2) C47833T (rs7903146).

\section{Statistical analysis}

Hardy-Weinberg equilibrium (HWE) was tested with the Allele Procedure in SAS, version 9.2 (SAS Institute Inc, Cary, NC). Distribution of alleles between the Inuit and Caucasian populations has previously been reported [7]. After completion of the recruitment, a group of 501 participants was calculated to provide an $80 \%$ probability and $5 \%$ significance level of detecting an anticipated difference of $0.10 \mathrm{mmol} / \mathrm{L}$ for TG concentrations (primary outcome) with a genetic variation that occurs in a relatively low frequency ( $>10 \%)$ of the population.

Data are shown as mean \pm standard error of mean ( $\mathrm{S}$. E.M). Further, variables were checked for normality. Plasma TG and ratio TC/ HDL-C were transformed by natural logarithm to normalize their distribution. A statistical model was used to evaluate the effect of the polymorphism, RBC percentage of total $n-3$ PUFA as a continuous variable, and the polymorphism by RBCs percentage of total $n$-3 PUFA interaction effect, adjusted for the effects of age, sex, BMI, and total energy intake (kcal) on each of the lipid variables. Then, the absolute values of the regression beta- $(\beta)$ coefficient were derived to estimate the phenotypic difference contributed by each of the genotype by RBC percentage of total $n-3$ PUFA interaction effect. In addition, to test for the additive effects of multiple polymorphisms, a "risk score" was calculated based on the number of risk genotypes an individual carried from all the significant polymorphism by RBCs percentage of total $n-3$ PUFA interactions for each lipid parameter. A statistical model was used to evaluate the effect of the "risk score", RBCs percentage of total $n-3$ PUFA as a continuous variable, and the risk score by RBCs percentage of total $n$ - 3 PUFA interaction effect, adjusted for the effects of age, sex, BMI and energy intake (kcal) on each of the lipid variables. Again, the absolute value of the regression $\beta$ - coefficient was calculated to estimate the phenotypic difference contributed by the number of risk genotypes and percentage of total $n-3$ PUFA in RBCs interaction effects. When significant differences were found, a comparison pairwise was performed in a global analysis (Tukey tests; significance $P \leq 0.05)$. Statistical analyses were performed with SAS statistical software, version 9.2 (SAS Institute Inc, Cary, NC).

\section{Results}

\section{Phenotypic characteristics}

In summary, 677 households were contacted of which 521 agreed to participate including 1056 individuals who signed a consent form and 917 who agreed to the collection of blood samples. In addition, 769 participants completed the FFQ. For the additional genetic component, 658 individuals from the original individuals gave consent. Consequently, the statistical analyses were done for all individuals where plasma lipid concentrations, percentage of total $n-3$ PUFA in RBCs, energy intake and genotypes were available. Therefore, 553 participants were included. The baseline characteristics, plasma lipids levels, percentage of total $n-3$ PUFAs in RBCs, and daily energy intake are described in Table 2. Briefly, higher RBC percentages of $n-3$ PUFA in the Inuit population were associated to lower TG concentrations $(P=0.0119)$, higher TC $(P=0.0001)$ including higher HDL-C $(P<$ 
Table 2 Baseline characteristics of the study subjects

\begin{tabular}{lll}
\hline & Men $(\mathbf{n}=\mathbf{2 5 1})$ & Women $(\mathbf{n}=\mathbf{3 0 2})$ \\
\hline Anthropometrics & & \\
Age & $37.1 \pm 0.9$ & $37.3 \pm 0.8$ \\
Weight (kg) & $74.5 \pm 1.0$ & $65.9 \pm 0.9$ \\
Height (cm) & $165.8 \pm 0.4$ & $154.0 \pm 0.3$ \\
BMI (Kg/m ${ }^{2}$ ) & $27 \pm 0.3$ & $28 \pm 0.4$ \\
Hypercholesterolemia (n,\% of total) & $22(9 \%)$ & $21(7 \%)$ \\
Plasma Lipids & & \\
Total Cholesterol (mmol/L) & $4.94 \pm 0.06$ & $5.04 \pm 0.05$ \\
HDL- Cholesterol (mmol/L) & $1.48 \pm 0.02$ & $1.79 \pm 0.03$ \\
LDL- Cholesterol (mmol/L) & $2.89 \pm 0.06$ & $2.74 \pm 0.05$ \\
Total/HDL- Cholesterol ratio & $3.52 \pm 0.07$ & $2.96 \pm 0.05$ \\
Triglycerides (mmol/L) & $1.25 \pm 0.04$ & $1.11 \pm 0.04$ \\
ApoB100 (mmol/L) & $0.97 \pm 0.02$ & $0.93 \pm 0.01$ \\
ApoA1 (mmol/L) & $1.62 \pm 0.02$ & $1.77 \pm 0.02$ \\
$\boldsymbol{n}$-3 PUFA in RBCs & & \\
Eicosapentaenoic acid (EPA) (\%) & $1.52 \pm 0.08$ & $1.82 \pm 0.07$ \\
Docosapentaenoic acid (DPA) (\%) & $2.17 \pm 0.03$ & $2.21 \pm 0.03$ \\
Docosahexaenoic acid (DHA) (\%) & $5.11 \pm 0.12$ & $5.80 \pm 0.11$ \\
Total $n-3$ PUFAs (\%) & $9.14 \pm 0.22$ & $10.19 \pm 0.20$ \\
Daily Intake & & \\
Total Energy Intake (KJ) & $10932 \pm 352$ & $9291 \pm 301$ \\
\hline
\end{tabular}

Total percentage of $n-3$ PUFAs in RBCs was calculated from the sum of $C 18: 3$ $(n-3), C 18: 4(n-3), C 20: 4(n-3), C 20: 5(n-3)(E P A), C 22: 3(n-3), C 22: 5(n-3)(D P A)$, and C22:6 (n-3) (DHA).

0.0001) and higher LDL-C concentrations $(P=0.0146)$ without changing the TC/HDL ratio and plasma apoB100 levels when adjusted for age, sex, BMI and energy intake.

\section{Genotypic characteristics}

Genotype frequencies did not deviate from those predicted by the Hardy-Weinberg equilibrium except for the following 3 SNPs: LPL HindIII (rs320), LPL Ser447Ter (rs328) and TCF7L2 C47833T (rs7903146) which were excluded from statistical analyses. The minor alleles of the following SNPs: AGT T174M (rs4762), AGT A-20C (rs5050), APOA5 Gly185Cys (rs2075291), APOA5 S19W (rs3135506), APOE Cys112Arg (rs429358), and FTO (rs9939609) had low frequencies $(\mathrm{MAF}<0.10)$ in the Inuit population and were also excluded from analyses. In addition, allele frequencies were significantly different $(P \leq 0.05)$ in 18 SNPs in the Inuit population comparatively to the Caucasian population, as previously described [7].

\section{Gene- diet interactions for CVD risk factors}

Statistical analyses revealed 8 SNPs by percentage of $n-3$ PUFA in RBCs interactions for plasma lipid concentrations (Table 3). Briefly, subjects heterozygous for CETP C4502T (rs183130) or G-971A (rs4783961) had significantly lower plasma TG concentrations with higher $n$-3 PUFA percentage in RBCs compared to homozygotes for the minor allele. In addition, a more favorable plasma lipid profiles when higher percentages of $n$-3 PUFA were observed: lower plasma $\mathrm{TC}$ for $\mathrm{T}$ carriers of CETP C4502T (rs183130) or lower plasma TC/HDL ratio for CETP G971A (rs4783961) for AG genotype. Participants homozygous for the T allele of CETP Ile405Val (rs5882) had lower plasma TC and T carriers of CETP Ile405Val (rs5882) had higher plasma HDL-C concentrations when higher percentage of $n$-3 PUFA in RBCs were observed. Secondly, for APOA5, G carriers of $-3 \mathrm{~A} / \mathrm{G}$ (rs651821) or $\mathrm{C}$ carriers of T-1131C (rs662799) exhibited higher plasma LDL-C concentrations, lower plasma HDL-C concentrations, a higher plasma TC/HDL ratio as well as higher apoB100 levels when they had a higher percentage of total $n-3$ PUFA in RBCs. Thirdly, carriers of the mutated allele of $A G T$ M235T (rs699), compared to wild-type genotype, had decreased plasma TC and LDL-C concentrations when higher $n$-3 PUFA percentage were observed. Forth, $\mathrm{G}$ allele carriers of APOA4 Asn147Ser (rs5104) had greater apoB100 concentrations with higher percentage of $n-3$ PUFA. Finally, subjects carrying the $\mathrm{G}$ allele of $A P O C 3 \mathrm{SstI}$ (rs5128) had increased TC/ HDL ratio and apoB100 concentrations with higher percentage of $n-3$ PUFA. Additionally, a higher number of these above "risk alleles" in interaction with percentage of total n-3 PUFA were associated with significantly higher TG $(P=0.0069)$, TC $(P=$ $0.0010)$, LDL-C $(P=0.0025)$ and apoB100 $(P=0.0044)$ concentrations as well as TC/HDL-C ratio $(P=0.0004)$ together with lower HDL-C $(P=0.0030)$ concentrations. Overall, polymorphisms in CETP, AGT, APOA5, APOA4 and $A P O C 3$ and the percentage of $n-3$ PUFA in RBCs are associated with plasma lipid concentrations in the Inuit population.

\section{Discussion}

Results suggest that genetic factors and the percentages of $n-3$ PUFA in RBCs influence CVD risk factors in the Inuit population. Specifically, results demonstrate that 8 SNPs in 5 candidate genes: CETP ((rs5882) (rs183130) and (rs4783961)), AGT (rs699), APOA5 ((rs651821) and (rs662799)), APOA4 Asn147Ser (rs5104), and APOC3 (rs5128), are associated with plasma lipid concentrations in interaction with the percentages of $n-3$ PUFA in RBCs in the Inuit population.

Higher percentage of $n-3$ PUFA in the Inuit population were associated with lower TG levels, higher TC including HDL-C and LDL-C concentrations without affecting the TC/HDL ratio and plasma apoB100 levels. In the same way, a meta-analysis that combined 21 trials with consumption of fish oil, reported a decrease in plasma TG concentrations and an increase in HDL-C and LDL-C concentrations without changes in TC 
Table 3 Impact of the SNP, RBCs total n-3 PUFA and the interaction SNP * RBCs total n-3 PUFA on plasma lipids and lipoproteins levels

\begin{tabular}{|c|c|c|c|c|c|c|}
\hline & SNP & $\begin{array}{l}\text { P-value for } \\
\text { SNP }\end{array}$ & $\begin{array}{l}\text { P-value for RBC } \\
\text { total n-3 PUFA }\end{array}$ & $\begin{array}{l}\text { Genotype/ } \\
\text { Frequency }\end{array}$ & $\beta \pm \mathrm{SEM}$ & $\begin{array}{l}\text { P-Value for } \\
\text { Interaction effect }\end{array}$ \\
\hline \multirow[t]{9}{*}{ Total cholesterol (TC) } & $A G T$ & 0.1453 & 0.4455 & C/C (71\%) & $0^{\mathrm{a}}$ & 0.0448 \\
\hline & M235T & & & $C / T(26 \%)$ & $0.0210 \pm 0.0262^{\mathrm{a}}$ & \\
\hline & rs699* & & & $\mathrm{T} / \mathrm{T}(3 \%)$ & $-0.1482 \pm 0.0651^{b}$ & \\
\hline & CETP & 0.0152 & $<0.0001$ & C/C (36\%) & $0^{a}$ & 0.0326 \\
\hline & C-4502T & & & $\mathrm{C} / \mathrm{T}(49 \%)$ & $-0.0632 \pm 0.0241^{b}$ & \\
\hline & rs183130 & & & $\mathrm{T} / \mathrm{T}(15 \%)$ & $-0.0421 \pm 0.0343^{\mathrm{ab}}$ & \\
\hline & CETP & 0.1115 & 0.0002 & C/C (26\%) & $0^{\mathrm{ab}}$ & 0.0334 \\
\hline & Ile405Val & & & $\mathrm{C} / \mathrm{T}(47 \%)$ & $0.0397 \pm 0.0268^{\mathrm{a}}$ & \\
\hline & rs5882* & & & $\mathrm{T} / \mathrm{T}(26 \%)$ & $-0.0290 \pm 0.0307^{b}$ & \\
\hline \multirow[t]{9}{*}{ LDL-Cholesterol (LDL-C) } & AGT & 0.1514 & 0.6339 & C/C (71\%) & $0^{\mathrm{a}}$ & 0.0405 \\
\hline & M235T & & & $\mathrm{C} / \mathrm{T}(26 \%)$ & $0.0299 \pm 0.0238^{a}$ & \\
\hline & rs699* & & & $\mathrm{T} / \mathrm{T}(3 \%)$ & $-0.1228 \pm 0.0592^{b}$ & \\
\hline & APOA5 & 0.012 & 0.0018 & $\mathrm{~A} / \mathrm{A}(42 \%)$ & $0^{\mathrm{a}}$ & 0.006 \\
\hline & $-3 \mathrm{~A} / \mathrm{G}$ & & & $\mathrm{G} / \mathrm{A}(45 \%)$ & $0.0678 \pm 0.0213^{b}$ & \\
\hline & rs651821 & & & G/G (13\%) & $0.0474 \pm 0.0332^{\mathrm{ab}}$ & \\
\hline & APOA5 & 0.0137 & 0.0035 & $\mathrm{~T} / \mathrm{T}(42 \%)$ & $0^{\mathrm{a}}$ & 0.0072 \\
\hline & $\mathrm{T}-1131 \mathrm{C}$ & & & $\mathrm{T} / \mathrm{C}(44 \%)$ & $0.0669 \pm 0.0213^{b}$ & \\
\hline & rs662799 & & & C/C (34\%) & $0.0427 \pm 0.0339^{\mathrm{ab}}$ & \\
\hline \multirow[t]{9}{*}{ HDL-Cholesterol (HDL-C) } & APOA5 & 0.126 & 0.0002 & $\mathrm{~A} / \mathrm{A}(42 \%)$ & $0^{\mathrm{a}}$ & 0.0065 \\
\hline & $-3 \mathrm{~A} / \mathrm{G}$ & & & G/A (45\%) & $-0.0317 \pm 0.0100^{b}$ & \\
\hline & rs651821 & & & G/G (13\%) & $-0.0105 \pm 0.0155^{\mathrm{ab}}$ & \\
\hline & APOA5 & 0.01476 & 0.0002 & $\mathrm{~T} / \mathrm{T}(42 \%)$ & $0^{\mathrm{a}}$ & 0.0072 \\
\hline & $\mathrm{T}-1131 \mathrm{C}$ & & & T/C (44\%) & $-0.0314 \pm 0.0100^{b}$ & \\
\hline & rs662799 & & & C/C (34\%) & $-0.0115 \pm 0.0159^{\mathrm{ab}}$ & \\
\hline & CEPT & 0.2302 & 0.0017 & C/C (26\%) & $0^{\mathrm{a}}$ & 0.0271 \\
\hline & lle405Val & & & $\mathrm{C} / \mathrm{T}(47 \%)$ & $0.0263 \pm 0.0115^{b}$ & \\
\hline & rs5882* & & & $\mathrm{T} / \mathrm{T}(26 \%)$ & $0.0017 \pm 0.0131^{\mathrm{a}}$ & \\
\hline \multirow[t]{6}{*}{ Triglycerides (TG) } & CETP & 0.0092 & 0.3779 & C/C (36\%) & $0^{\mathrm{ab}}$ & 0.0300 \\
\hline & C-4502T & & & T/C (49\%) & $-0.0095 \pm 0.0051^{a}$ & \\
\hline & rs183130 & & & $\mathrm{T} / \mathrm{T}(15 \%)$ & $0.0073 \pm 0.0073^{b}$ & \\
\hline & CETP & 0.0087 & 0.399 & G/G (28\%) & $0^{\mathrm{ab}}$ & 0.0032 \\
\hline & G-971A & & & $\mathrm{A} / \mathrm{G}(50 \%)$ & $-0.0106 \pm 0.0057^{\mathrm{a}}$ & \\
\hline & rs4783961 & & & A/A (22\%) & $0.0087 \pm 0.0068^{b}$ & \\
\hline \multirow{10}{*}{$\begin{array}{l}\text { Ratio Total Cholesterol/ } \\
\text { HDL-Cholesterol }\end{array}$} & APOC3 & 0.2263 & 0.7503 & C/C (33\%) & $0^{\mathrm{a}}$ & 0.0137 \\
\hline & Sstl & & & C/G (46\%) & $0.0081 \pm 0.0030^{b}$ & \\
\hline & rs5128* & & & G/G (21\%) & $0.0085 \pm 0.0039^{b}$ & \\
\hline & APOA5 & 0.0016 & 0.5195 & $\mathrm{~A} / \mathrm{A}(42 \%)$ & $0^{\mathrm{a}}$ & $<0.0001$ \\
\hline & $-3 \mathrm{~A} / \mathrm{G}$ & & & G/A (45\%) & $0.0128 \pm 0.0028^{b}$ & \\
\hline & rs651821 & & & G/G (13\%) & $0.0053 \pm 0.0044^{\mathrm{ab}}$ & \\
\hline & APOA5 & 0.0018 & 0.62 & $\mathrm{~T} / \mathrm{T}(42 \%)$ & $0^{\mathrm{a}}$ & $<0.0001$ \\
\hline & $\mathrm{T}-1131 \mathrm{C}$ & & & $\mathrm{T} / \mathrm{C}(44 \%)$ & $0.0126 \pm 0.0028^{b}$ & \\
\hline & rs662799 & & & C/C (14\%) & $0.0050 \pm 0.0045^{\mathrm{ab}}$ & \\
\hline & CETP & 0.188 & 0.8473 & G/G (28\%) & $0^{\mathrm{ab}}$ & 0.0483 \\
\hline
\end{tabular}


Table 3 Impact of the SNP, RBCs total n-3 PUFA and the interaction SNP * RBCs total n-3 PUFA on plasma lipids and lipoproteins levels (Continued)

\begin{tabular}{|c|c|c|c|c|c|c|}
\hline & G-971A & & & $\mathrm{A} / \mathrm{G}(50 \%)$ & $-0.0055 \pm 0.0033^{a}$ & \\
\hline & rs4783961 & & & A/A (22\%) & $0.0022 \pm 0.0039^{b}$ & \\
\hline \multirow[t]{12}{*}{ ApoB100 } & APOC3 & 0.0374 & 0.0399 & C/C (33\%) & $0^{\mathrm{a}}$ & 0.0073 \\
\hline & Sstl & & & C/G (46\%) & $0.0179 \pm 0.0058^{b}$ & \\
\hline & rs5128* & & & G/G (21\%) & $0.0145 \pm 0.0076^{a b}$ & \\
\hline & APOA4 & 0.0277 & 0.0221 & $\mathrm{~A} / \mathrm{A}(33 \%)$ & $0^{\mathrm{a}}$ & 0.0052 \\
\hline & Asn147Se & & & $\mathrm{A} / \mathrm{G}(45 \%)$ & $0.0178 \pm 0.0058^{b}$ & \\
\hline & rs5104 & & & G/G (22\%) & $0.0177 \pm 0.0073^{b}$ & \\
\hline & APOA5 & 0.0006 & 0.091 & $\mathrm{~A} / \mathrm{A}(42 \%)$ & $0^{a}$ & 0.0002 \\
\hline & $-3 \mathrm{~A} / \mathrm{G}$ & & & G/A (45\%) & $0.0229 \pm 0.0055^{b}$ & \\
\hline & rs651821 & & & G/G (13\%) & $0.0086 \pm 0.0086^{\mathrm{ab}}$ & \\
\hline & APOA5 & 0.0009 & 0.0516 & $\mathrm{~T} / \mathrm{T}(42 \%)$ & $0^{\mathrm{a}}$ & 0.0002 \\
\hline & $\mathrm{T}-1131 \mathrm{C}$ & & & T/C (44\%) & $0.0227 \pm 0.0055^{b}$ & \\
\hline & rs662799 & & & C/C (34\%) & $0.0117 \pm 0.0088^{\mathrm{ab}}$ & \\
\hline
\end{tabular}

$\beta$ regression coefficient, $P$ values are calculated with normalized values; $\beta$ regression coefficient are derived from absolute values, ${ }^{a, b}$ Means with different subscript letters for one SNP are significantly different after adjustment for Tukey test; * Genotype frequency is different between the Inuit and Caucasian populations; The model includes the SNP, n-3 PUFA in RBCs, and the interaction term with adjustment for the effects of age, sex, BMI, and daily energy intake.

concentrations [18]. Thus, the beneficial effects of higher percentages of $n-3$ PUFA in RBCs on CVD risk factors in the Inuit population are similar to those previously reported; however, gene-nutrient interactions contribute the inter-individual variability observed in the plasma lipid levels in this population.

Heterozygotes for CETP C4502T (rs183130) or G971A (rs4783961) had lower plasma TG concentrations with higher percentages of $n$ - 3 PUFA compared to the homozygotes for the minor allele. In addition, these heterozygotes for CETP C4502T or G-971A had lower plasma TC levels or TC/HDL ratio with higher percentages of $n$-3 PUFA compared to homozygotes for the rare allele, respectively. CETP plays a central role in HDL-C metabolism by shuttling cholesteryl esters from HDL particles to apoB- containing particles, partly in exchange for TG [19]. It is well-known that several genetic variants in the CETP gene are associated with altered plasma HDL-C concentrations, lipoprotein particle sizes, CETP plasma concentrations and activity, and perhaps the risk of coronary artery disease [19]. Earlier, Corella et al., [20] demonstrated no gene-environment interactions, including total fat, saturated fat and monounsaturated fat- for the CETP C4502T SNP on HDL-C concentrations. We have also demonstrated no interaction with total fat or saturated fat intake with this SNP on plasma lipid levels [7]; however, in the present study, the inclusion of $n$-3 PUFA in the diets of wild-type or heterozygotes for CETP would favor an improved cardiovascular risk profile compare to carriers of the minor allele.

Further, carriers of the $\mathrm{T}$ allele for CETP Ile405Val (rs5882) decreased plasma TC and increased plasma
HDL-C concentrations with higher percentages of $n-3$ PUFA. This functional SNP, corresponding to the substitution of a valine for an isoleucine caused by a $\mathrm{C} \rightarrow \mathrm{T}$ mutation, has been associated with lower CVD risk via lowering of CETP protein concentration and activity; consequently, increasing HDL-C levels and lipoprotein particle sizes [21]. Previously, Darabi et al., [22] demonstrated that subjects carrying the $\mathrm{C}$ allele of CETP Ile405Val had greater reduction in plasma HDL-C and apoAI concentrations than subjects carrying a $\mathrm{T}$ allele when a high-PUFA: saturated diet was replaced with a low- PUFA: saturated diet [22]. Together, these studies suggest that PUFA intake in individuals with CETP Ile405Val polymorphism contributes to the variability of plasma lipids concentrations.

Similarly, higher percentage of $n$ - 3 PUFA in carriers of the T allele of AGT M235T (rs699) were associated with lower plasma TC and LDL-C concentrations than carriers of the wild-type allele. The M235T polymorphism in the $A G T$ gene has been associated to an increased CVD risk in the presence of hypercholesterolemia [23]. In a previous study with this Inuit population, we demonstrated that carriers of the minor allele of M235T $A G T$ with high total and saturated fat intake exhibited higher plasma TC and LDL-C concentrations [7]. Taken together, these results suggest that carriers of the $A G T$ M235T should consume a diet high in $n-3$ PUFA and low in saturated fat, to reduce their risk of CVD.

In contrast, $\mathrm{G}$ allele carriers of APOA5 -3 A/G (rs651821) or C allele carriers of APOA5 T-1131C (rs662799) had a more deteriorated lipid profile including higher plasma LDL-C and apoB100 concentrations, 
a higher TC/HDL ratio together with lower plasma HDL$C$ concentrations with higher percentage of $n-3$ PUFA in RBCs. APOA5 regulates TG metabolism; therefore, different SNPs in APOA5 may be associated with TG concentrations and CVD risk factors [24]. Variations in this gene have been previously associated with plasma lipid levels via modulation of dietary intake. First, an interaction of the APOA5 $\mathrm{T}-1131 \mathrm{C}$ polymorphism with energy intake and total fat was observed for plasma TG and TC concentrations in a population of Puerto Rican older adults [25]. Secondly, a study in the Mediterranean population reported a positive association between fat intake and obesity in homozygotes for the $\mathrm{T}$ allele of APOA5 T$1131 \mathrm{C}$, whereas in subjects carrying the APOA5 T-1131C polymorphism, higher fat intakes were not associated with higher BMI and TG-rich lipoproteins [26]. Finally, Lai et al., [27] suggest that high PUFA-rich diets, specifically n-6 PUFAs, are related to a more atherogenic lipid profile in individuals of the Framingham Heart Study with the APOA5 T-1131C polymorphism. Overall, results suggest that SNPs in APOA5 are determinants of variation in lipid response to $n-3$ PUFA intake; however, the outcome of these gene-nutrient interactions needs to be investigated further.

Further, carriers of the $\mathrm{G}$ allele of $A P O A 4$ Asn147Ser (rs5104) had higher apoB100 levels with higher percentages of $n$-3 PUFA in RBCs. It has been suggested that APOA4 plays an important role in the metabolism of TG-rich lipoproteins [28]. APOA4 variants may alter protein and thus have been linked to baseline TG concentrations [28] and TG in response to fenofibrate treatment [29]. A study demonstrated that carriers of the minor allele of APOA4 Asn147Ser had lower plasma apoA1 concentrations in a postprandial state after a high saturated meal [24]. Together, results demonstrate that carriers of the minor allele of APOA4 Asn147Ser may be more sensitive to changes in dietary fat.

Similarly, carriers of the APOC3 G minor allele of SstI (rs5128) had increased $\mathrm{TC} / \mathrm{HDL}$ ratio and plasma apoB100 concentrations with higher percentages of $n-3$ PUFA. APOC3 increases plasma TG concentrations by inhibiting the lipoprotein lipase activity and by altering the Apo-E mediated uptake of TGs. The G- allele has been associated with elevated plasma TC, TG, and apoCIII concentrations [30]. Lopez-Miranda et al., [31] demonstrated an increase in plasma LDL-C concentrations in the CC subjects after consumption of a diet high in monounsaturated fatty acids whereas a decrease was observed in the CG subjects. Taken as a whole, results demonstrate that carriers of the APOC3 G allele of SstI may benefit more from a high monounsaturated diet compared to an n-3 PUFA diet.

Since the effect size of each SNP was small even if the interaction was statistically significant, we demonstrated an additive effect of these SNPs in interaction with percentage of $n$ - 3 PUFA for all CVD risk factors. Thus, this demonstrates that it is possible to develop models with advantageous and disadvantageous alleles together with dietary intake data and predict the risk of a deteriorated lipid profile in a specific population. However, the major limitation for the study is the limited number of SNPs chosen based on previous research findings. If such models would be developed, large studies using numerous genetic variations should be included to be able to assess the greatest variability.

\section{Conclusions}

Overall, these results suggest that the percentages of $n-3$ PUFA in RBCs, as an indicator of $n-3$ PUFA intake and genetic variations in CETP, AGT, APOA5, APOA4 and $A P O C 3$, in the Inuit population are associated with CVD risk factors. In general, $n-3$ PUFA consumption has favorable effects on lipid related CVD risk factors; however, some genetic subgroups may benefit to greater extent from a higher intake of $n-3$ PUFA for lipid related CVD risk factors.

\section{Abbreviations}

FAs: Fatty acids; CVD: Cardiovascular disease; RBCs: Red blood cells; PUFA: Polyunsaturated fatty acids; TG: Triacylglycerol; TC: Total cholesterol; LDL-C: Low-density lipoprotein cholesterol; HDL-C: High-density lipoprotein cholesterol; IHD: Ischemic heart disease; apo: Apolipoprotein;

EPA: Eicosapentaenoic acid; DHA: Docosahexaenoic acid; DPA: Docosapentaenoic acid; ACE: Angiotensin I converting enzyme; AGT: Angiotensinogen; APOA1: Apolipoprotein A-l; APOA4: Apolipoprotein AIV; APOA5: Apolipoprotein A-V; APOB: Apolipoprotein B;

APOC3: Apolipoprotein C-III; APOE: Apolipoprotein E; ABC1: ATP-binding cassette, sub-family A; ABC1A: Member 1; CETP: Cholesteryl ester transfer protein; CYP1A1: Cytochrome P450, family 1, subfamily A, polypeptide 1; FTO: Fat mass and obesity associated; GCKR: Glucokinase (hexokinase 4) regulator; INSIG2: Insulin induced gene 2; LPL: Lipoprotein lipase; HL or LIPC: Hepatic lipase; NAD(P)H MTHFR: Methylenetetrahydrofolate reductase; PON1: Paraoxonase 1; PPARG2: Peroxisome proliferator-activated receptor gamma 2; TCF7L2: Transcription factor 7-like 2; HWE: Hardy-Weinberg equilibrium.

\section{Competing interests}

The authors declare that they have no competing interests.

\section{Authors' contributions}

IR performed statistical analysis, interpreted data and wrote the paper; CO performed statistical analysis; $V B, A D L, B A, F P, Y G$, and MLCD were responsible for data collection and analysis including genotyping, nutrient intakes and lipid parameters in the original study; ED, RAH and MCV were responsible for the study design; all authors contributed to the critical revision of the article; IR and MCV have primary responsibility for final content. All authors read and approved the final manuscript.

\section{Acknowledgements}

We express our gratitude to the participants for their collaboration.

This work was supported by the Ministère de la santé et des services sociaux du Québec, the Nunavik Regional Board of Health and Social Services, the Network of Centres of Excellence of Canada (ArcticNet), the Nasivvik ACADRE Inuit Centre, Northern and Indian Affairs (Northern Contaminant Program) and the Canadian Institutes of Health Research (CIHR). Iwona Rudkowska is supported by a CIHR Bisby Postdoctoral Fellowship Award (200810BFE). Yves Giguère holds is a senior research scholarship from the Fonds de la 
Recherche en Santé du Québec (FRSQ). Marie-Claude Vohl holds a Tier 1 Canada Research Chair in Genomics Applied to Nutrition and Health.

\section{Author details}

'Institute of Nutrition and Functional Foods (INAF), Laval University, 2440, boulevard Hochelaga, Québec QC, Canada. ${ }^{2}$ Laboratory of Endocrinology and Nephrology, Laval University Hospital Research Center, Quebec, QC, Canada. ${ }^{3}$ Laboratory of Population and Environmental Health, Laval University Hospital Research Center, Quebec, QC, Canada. ${ }^{4}$ Robarts Research Institute, London, ON, Canada.

Received: 6 November 2012 Accepted: 3 March 2013

Published: 12 March 2013

\section{References}

1. Bjerregaard P, Young TK, Hegele RA: Low incidence of cardiovascular disease among the Inuit-what is the evidence? Atherosclerosis 2003, 166:351-357.

2. Lewington $S$, Whitlock $G$, Clarke R, Sherliker P, Emberson J, Halsey J, et al: Blood cholesterol and vascular mortality by age, sex, and blood pressure: a meta-analysis of individual data from 61 prospective studies with 55,000 vascular deaths. Lancet 2007, 370:1829-1839.

3. Blanchet C, Dewailly E, Ayotte P, Bruneau S, Receveur O, Holub BJ: Contribution of Selected Traditional and Market Foods to the Diet of Nunavik Inuit Women. Can J Diet Pract Res 2000, 61:50-59.

4. Mozaffarian D, Wu JH: Omega-3 fatty acids and cardiovascular disease: effects on risk factors, molecular pathways, and clinical events. J Am Coll Cardiol 2011, 58:2047-2067.

5. Lucas M, Proust F, Blanchet C, Ferland A, Dery S, Abdous B, et al: Is marine mammal fat or fish intake most strongly associated with omega-3 blood levels among the Nunavik Inuit? Prostaglandins Leukot Essent Fatty Acids 2010, 83:143-150.

6. Chateau-Degat ML, Dewailly E, Louchini R, Counil E, Noel M, Ferland A, et al: Cardiovascular burden and related risk factors among Nunavik (Quebec) Inuit: insights from baseline findings in the circumpolar Inuit health in transition cohort study. Can J Cardiol 2010, 26:190-196.

7. Rudkowska I, Dewailly E, Hegele RA, Boiteau V, Dube-Linteau A, Abdous B, et al: Gene-diet interactions on plasma lipid levels in the Inuit population. Br J Nutr 2013, 109:953-961.

8. Hegele RA, Young TK, Connelly PW: Are Canadian Inuit at increased genetic risk for coronary heart disease? J Mol Med 1997, 75:364-370

9. Dewailly E, Chateau-Degat ML, Ekoe JM, Ladouceur R, Rochette L: Nunavik Inuit Health Survey 2004, Qanuippitaa? How are we? In Québec: Institut national de santé publique du Québec (INSPQ) \& Nunavik Regional Board of Health and Social Services (NRBHSS). Status of Cardiovascular Disease and Diabetes in Nunavik. 2007.

10. Kuczmarski RJ, Flegal KM: Criteria for definition of overweight in transition: background and recommendations for the United States. Am J Clin Nutr 2000, 72:1074-1081.

11. McNamara JR, Schaefer EJ: Automated enzymatic standardized lipid analyses for plasma and lipoprotein fractions. Clin Chim Acta 1987, 166:1-8.

12. Friedewald WT, Levy Rl, Fredrickson DS: Estimation of the concentration of low-density lipoprotein cholesterol in plasma, without use of the preparative ultracentrifuge. Clin Chem 1972, 18:499-502.

13. Laurell CB: Quantitative estimation of proteins by electrophoresis in agarose gel containing antibodies. Anal Biochem 1966, 15:45-52.

14. Blanchet C, Rochette L: Nutrition and Food Consumption among the Inuit of Nunavik. Quebec, Canada: Institut national de santé publique du Québec \& Régie régionale de la santé et des services sociaux du Nunavik. Ref Type: Generic; 2008.

15. Ferland A, Lamarche B, Chateau-Degat ML, Counil E, Anassour-Laouan-Sidi E, Abdous B, et al: Dairy product intake and its association with body weight and cardiovascular disease risk factors in a population in dietary transition. J Am Coll Nutr 2011, 30:92-99.

16. Shaikh NA, Downar E: Time course of changes in porcine myocardial phospholipid levels during ischemia. A reassessment of the lysolipid hypothesis. Circ Res 1981, 49:316-325.

17. Lepage G, Roy CC: Direct transesterification of all classes of lipids in a one-step reaction. J Lipid Res 1986, 27:114-120.
18. Balk EM, Lichtenstein AH, Chung M, Kupelnick B, Chew P, Lau J: Effects of omega-3 fatty acids on serum markers of cardiovascular disease risk: a systematic review. Atherosclerosis 2006, 189:19-30.

19. Boekholdt SM, Kuivenhoven JA, Hovingh GK, Jukema JW, Kastelein JJ, van TA: CETP gene variation: relation to lipid parameters and cardiovascular risk. Curr Opin Lipidol 2004, 15:393-398.

20. Corella D, Carrasco P, Fito M, Martinez-Gonzalez MA, Salas-Salvado J, Aros F, et al: Gene-environment interactions of CETP gene variation in a high cardiovascular risk Mediterranean population. J Lipid Res 2010, 51:2798-2807.

21. Thompson A, Di AE, Sarwar N, Erqou S, Saleheen D, Dullaart RP, et al: Association of cholesteryl ester transfer protein genotypes with CETP mass and activity, lipid levels, and coronary risk. JAMA 2008, 299:2777-2788.

22. Darabi M, Abolfathi AA, Noori M, Kazemi A, Ostadrahimi A, Rahimipour A, et al: Cholesteryl ester transfer protein $1405 \mathrm{~V}$ polymorphism influences apolipoprotein A-I response to a change in dietary fatty acid composition. Horm Metab Res 2009, 41:554-558.

23. Zafarmand MH, van der Schouw YT, Grobbee DE, de Leeuw PW, Bots ML: The M235T polymorphism in the AGT gene and CHD risk: evidence of a Hardy-Weinberg equilibrium violation and publication bias in a metaanalysis. PLoS One 2008, 3:e2533.

24. Delgado-Lista J, Perez-Jimenez F, Ruano J, Perez-Martinez P, Fuentes F, Criado-Garcia J, et al: Effects of variations in the APOA1/C3/A4/A5 gene cluster on different parameters of postprandial lipid metabolism in healthy young men. J Lipid Res 2010, 51:63-73.

25. Mattei J, Demissie S, Tucker KL, Ordovas JM: Apolipoprotein A5 Polymorphisms Interact with Total Dietary Fat Intake in Association with Markers of Metabolic Syndrome in Puerto Rican Older Adults. J Nutr 2009, 139:2301-2308.

26. Sanchez-Moreno C, Ordovas JM, Smith CE, Baraza JC, Lee YC, Garaulet M: APOA5 gene variation interacts with dietary fat intake to modulate obesity and circulating triglycerides in a Mediterranean population. J Nutr 2011, 141:380-385.

27. Lai CQ, Corella D, Demissie S, Cupples LA, Adiconis X, Zhu Y, et al: Dietary intake of $n-6$ fatty acids modulates effect of apolipoprotein $A 5$ gene on plasma fasting triglycerides, remnant lipoprotein concentrations, and lipoprotein particle size: the Framingham Heart Study. Circulation 2006, 113:2062-2070.

28. Talmud PJ, Hawe E, Martin S, Olivier M, Miller GJ, Rubin EM, et al: Relative contribution of variation within the APOC3/A4/A5 gene cluster in determining plasma triglycerides. Hum Mol Genet 2002, 11:3039-3046.

29. Liu Y, Ordovas JM, Gao G, Province M, Straka RJ, Tsai MY, et al: Pharmacogenetic association of the APOA1/C3/A4/A5 gene cluster and lipid responses to fenofibrate: the genetics of lipid-lowering drugs and diet network study. Pharmacogenet Genomics 2009, 19:161-169.

30. Russo GT, Meigs JB, Cupples LA, Demissie S, Otvos JD, Wilson PW, et al: Association of the Sst-I polymorphism at the APOC3 gene locus with variations in lipid levels, lipoprotein subclass profiles and coronary heart disease risk: the Framingham offspring study. Atherosclerosis 2001, 158:173-181.

31. Lopez-Miranda J, Ordovas JM, Marin C: The Sstl polymorphic site at the apolipoprotein C-III gene predicts plasma low-density lipoprotein response to changes in dietary fat in young men. Circulation 1994, 90:I.

\section{doi:10.1186/1743-7075-10-26}

Cite this article as: Rudkowska et al:: Omega-3 fatty acids,

polymorphisms and lipid related cardiovascular disease risk factors in the Inuit population. Nutrition \& Metabolism 2013 10:26. 